\title{
First-year student's work and rest balance as an enabler to transition to adult learning
}

\author{
Živilè Nemickienè \\ Vilnius University \\ zivile.nemickiene@knf.vu.lt \\ Emilija Nemickaite \\ Lithuanian University of Health Sciences \\ emanemika@gmail.com
}

\begin{abstract}
The present research analyses one out of multiple challenges the first-year students face during their transition to academic life, namely, the first-year students' work and rest balance. The balance, if managed wisely, might become a strong enabler to a successful transition to university life. The study analyses a series of factors, such as the balance of work and rest of the first-year students, skills of time management and the psychological state during the first months at university. The study employs a comparative analysis to evaluate the average hours of work and rest per week of a first-year student comparing with the planned time. The data of students' work and rest balance was collected from the diary they were asked to record for two months. A focus group was comprised of twenty-five respondents of finance, twelve students of language and three of health science study programs at Lithuanian universities.
\end{abstract}

Keywords. Work and rest, diary, time management.

\section{Introduction}

The 21 st century makes a great emphasis on studies and students. In 2019, the percentage of graduates seeking to enter Lithuanian higher education institutions is higher than last year, which is almost $65 \%$ and is one per cent more than in 2018. The number of students enrolled in 2019 shows that the state funds 7,096 full-time study places in university studies and 4,674 in colleges, and these are places funded just for first-year students.

The efforts of the state government are quite considerable, but students' difficulties of adapting to adult learning often undermine the mutual expectations of both students and the state. This problem is not only Lithuanian students' problem as newcomers all over the world face these difficulties. Therefore, many studies, observations, and analyses have been conducted on the subject to determine the ability of first-year students to adapt and integrate into the adult education system.

Huge attrition during the first semester is a waste of financial and human resources (Hillman, 2005); moreover, it is a question of reputation of an educational institution (Ramsay, Elphinstone, Vivekananda. 2003) and finally, a painful statistical fact in self-assessment report 
for external experts-evaluators. Kantanis (2000) who studied students' changeover to university life and study mode states that even during the first semester period, students make a resolve to continue or quit studies. McInnes (2002), James, Krause and Jennings (2010) analysed students' overall involvement into studies and academic life, development and survival at studies. One of the most prominent factors to go to the wall was pointed out by Goldfinch (2007). The lack of self-management skills results in poor performance at university and dropping out of university. Hillman (2005) touched on the question of the first-year students' transition from secondary school to university in Australia. The scholar tried to elucidate the main points that are significant for both newcomers and universities during the process of transition into university academic life. She and other researchers - Hillman (2005), McInnis (2001), Williams (2000), emphasizes the highest percentage of failure among newcomers at universities. Approximately, according to studies Wintre, Yaffe (2000), Rickinson, Rutherford (1995), nearly $40 \%$ of first-year students quit their studies because of different expectations they had about the university life and the experience during the first year of studies. According to Goldfinch (2007), the necessity to earn money for tuition and living is a serious factor to leave studies. Cook (2004) adds to this that the attempt to earn for living leads to poor performance at studies, low grades and isolation from university life and its societies. Even when entering university, though successfully, most students feel pressure and tension (Greenbank, 2007), (Wintre, Yaffe, 2000). The result of all this is stress, which, according to Roberts (2000) and Truswell's (2019) research, in turn, leads to alcohol and drug problems. As anxiety and depression add up to the case, students often look to coping mechanisms like binge drinking and drugs. Thurber (2012) adds homesickness to those hardships and Brown (2013) discusses racism. Sinclair (2006) emphasises language, academic subjects, and technologies as intimidating factors for newcomers.

The overview of extensive scientific research has presented the current state and dynamic of the issue of a successful transition to university. Research reveals a variety of challenges the first-year students face during their transition to university life mode. The attempt of the present research is to investigate and understand the first-year students' balance of work and rest as one of the enablers to a successful transition to adult academic life and to reveal possible ways of this problem solving.

In order to reveal the reasons of newcomers' failure in adaptation to adult academic life, the following factors are to be considered, namely, the balance of work and rest of the firstyear students, their skills of time management and their psychological state during the first months at university. The subject matter of the research is a weekly study load of a first-year student of language and finance study programs in Lithuanian universities.

To reach the aim and objectives set in the present research, the method of the questionnaire was employed, seeking to identify the student's time planning skills. A weekly diary filling method helped to record students' activities during work and rest periods. Methods of scientific and comparative analysis were employed to present relevant theoretical underpinnings. The method of benchmarking and observation were applied.

Researchers all over the world keep studying our daily routine, diet and sleep habits of individuals of all ages. The results of long-term research highlighted eventually the differences of habits between women and men elucidating unfavourable impact on health in many cases. Academic youth, due to the specific nature of their activities, forms a special crop having specific factors affecting health adversely, working capacity, and physical condition. These factors are a huge mental workload, usually motionless activities, and lack of fresh air. It is abnormal if students spend up to ten or even twelve hours per day on studies and only three or four hours for rest and leisure. Multiple research literature presents data about insufficient rest 
and students' sleep duration. Every third student sleeps for less than six hours. Students eating habits are irrational, irregular, and they demonstrate rather low physical activity. The process of developing healthy lifestyles is a complex and long-lasting issue which is strongly influenced firstly by the family attitude to health, and secondly by the school and society as a whole. Purvaneckiene (2000) believes that one of the most important tasks of a modern higher education institution is to amend students' interaction and build a healthy lifestyle. Young people are the most receptive members of a society; therefore, the focused formation of a healthy lifestyle will help to develop a healthy and perfect personality.

\section{Psychological and pedagogical characteristics of a young person}

As Kralikauskas (1998) states, youth is a time of severe crises, great doubts, fluctuations and searching. Literary works of young people from the fourteenth to a twentiethyear-old, such as diaries, letters, or poems, are taken as the main material for the psychological studies. Nowadays, blogging or diary writing is widely recognized as the best source for psychology research of youth. They can be treated as a specific mental document of young adults and adolescents. Psychologists see them as documents that allow researchers to reveal the stage of mental development of the very moment the diary was written.

The young person's life is a time of psychological and pedagogical confusion. It is a period of attitude changes, self-awareness, and understanding of the world. It is time for making a turn from the outside towards inside, towards the inner world. Then the attention is focused on personal inner sensations and experiences. The customs and authorities are critically evaluated, and willingness to check everything, to validate the truth is very strong. The greatest value for a young man is freedom; therefore, the youth is constantly fighting, rebelling, and conflicting with their parents and the people roundabout. They seek to be and prove they are independent and able to take care of themselves.

Along with the elements of adult status, young adults still retain some features of dependence. Their position somewhat reminds that of a child. The senior school students still fully depend on their parents. At school, on the one hand, they are told that they are adults, and on the other, they are required to show obedience constantly. In Lithuania sometimes this is true even for 20-year-olds who are not considered adults in certain circumstances, e.g. according to Lithuanian laws, young people over the age of eighteen can get married, defend their homeland with a gun, but cannot buy alcohol before the age of twenty-one. According to Petrovskis (1987), the uncertainty of this situation (in some cases they are accepted as adults, in other cases they are not) and the requirements placed upon them, reflect in their psychological state.

Thus, choosing a profession is the first step to independent social life, and the chosen profession indicates a position in society. It is the very moment when young people begin to appreciate the completeness of life. And then the statement "I live here and now" disappears. They are determined to pursue set goals, to create projects and future prospects.

\section{Basics of student activities, rest physiology and hygiene}

Planning the balance of work and rest means a rational combination of various activities and rest at a certain point in time. Vaitkevičius (2003) describes it as a combination of reflexes of certain conditioned and unconditional actions and time, which at the same time form very close neuropsychological connections. In fact, it is a dynamic stereotype, a chain of conditioned and/or unconditioned reflexes embedded in the cerebral cortex.

Activities and rest time of a young adult consist of such elements as nutrition, housekeeping, studying, social activities, etc. Thus, if time management is rational and well 
planned, it positively affects the health, physical and mental activity of the young adult and his/her psycho-emotional state.

A well-planned balance of activities and rest helps children, adolescents and young adults to overcome not only the problems of physical, but also mental development. The skills of self-knowledge, communication, cooperation, decision-making and implementation will strengthen the dynamic stereotype of activity and recreation. Rational time management will solve all the problems of mental and physical development of children, adolescents and youth.

Young people should be aware that the balance between work and rest, as well as rational planning of this balance, are of paramount importance to them and personal experience might help to understand this. Having acquired the basics of activity and physiology of rest, they could behave more flexibly and independently in different situations, such as giving up "fashion" or peer pressure on addictive habits, laziness, etc.

\section{Research design}

A focus group was comprised of twenty-five students of finance, twelve students of language and three of heath science study programs at Lithuanian universities. The organization of the research of work and rest management peculiarities for the first-year students was started by instructing students on the course of the research and their responsibilities, etc. forty respondents were familiarized with data collection methods, i.e. weekly filling blog for two months (mid-Oct. - mid-Dec.) and the questionnaire. The theoretical underpinning of the research is based on scientific literature using a comparative scientific method of analysis. Students of different universities have demonstrated the same tendencies in time management; it had no sense to discern the results of different institutions when analysing data.

After analysing the respondents' questionnaire, it was assumed that everyone lacks time planning skills. The answers in the questionnaires revealed that nearly all respondents were on the verge of chaos. An analysis of weekly diaries also showed that first-year students lacked the skills to plan work and rest hours. Thus, in these two analyses, students were found to have gaps in their time planning. Analysis of the diary clearly showed that the emotional state is not positive. Consequently, respondents are not satisfied with their time and rest management; however, the lack of skills and motivation prevents them from planning more accurately. Based on the recorded data, the analysis was performed.

\section{Analysis of a first-year student study-load}

Research tools of the research are methods of scientific and comparative analysis. A comparative analysis was employed to compare the hours of work and rest per week of a firstyear student with the planned time, which makes eight hours for work, eight hours for sleep, and eight hours for rest. This balance of hours is based on the first-year student's weekly diary. Weekly monitoring, work and rest recording helped to reveal and evaluate the peculiarities of student time management.

In the qualitative stage of the research uses data obtained from the questionnaire, which provided ten statements and the diary which first-year students were asked to complete for two months. The questionnaire offered the following open-ended questions:

\section{I think that day-to-day planning is a waste of time.}

The respondent states his/her opinion on time planning without knowing the results. The answer informs about the respondent's general approach to time management and a positive answer to this question indicates that the respondent is not interested in time planning. Students describe their life as a constant routine that is not necessary to plan. 


\section{My learning goals are clear enough.}

This question shows whether respondents have clear goals and know what they are striving for. Without knowing the goal, it is impossible to plan for the time. The answer to this question demonstrates the researcher's attitude and knowledge in the professional field. A negative answer indicates that students do not have sufficient knowledge about the learning objectives, which negatively affects their time planning. It is also related to an unwillingness to seek guidance or help from qualified academic staff. Most of the time, the newcomers followed the precursors' practice and advice via Facebook or face to face communication.

\section{Procrastinating tasks until the last minute is a big problem for me.}

The answer to this question demonstrates the respondent's understanding of the procrastination problem. Respondents do not admit they have problems with completing tasks on time; thus, they do not plan when they are going to complete them, though procrastination according to the diary has financial, psychological and social reasons.

\section{I organize my time very well.}

It is important to ask this question to find out the student's approach to time management. A positive answer indicates that students correctly assess their knowledge of time management and understand the inadequacy of that knowledge.

\section{I would like to be more motivated to plan my time.}

Perception of the general quality of studying allows students to plan their time in a motivated way; however, if respondents do not understand the meaning of knowledge, they answer this question negatively.

6. It is easy for me to finish or postpone a conversation with people who come over while I am studying.

This question helps to find out how respondents are able to allocate their time to complete necessary and unimportant tasks and if they are able to say NO to various distractions. If respondents give a negative answer, they not ready to complete intended plans and take a chance to defer them. It should be emphasized that the "distracting factor" should be understood not only as a lively presence of visitors but also as a presence on social networks and smartphones, which can distract students more often and disrupt their focus. Students should turn off the sound or, even better, remove their phones and other gadgets from their eyes. It is important to pay more attention to modern technology than it did before. The inability to stop distractors is one of the reasons for procrastination, which respondents basically do not admit. On the other hand, this socialization during the first months of academic life is sometimes vital.

\section{People feel free to visit me at any time.}

The answer gives a hint about the attitude of others towards the respondent's time, i.e. time devoted to communication. The question answered affirmatively proves that guests take liberties with the respondents' time because the respondents are not able to show that they have important or urgent work, and communication should be postponed.

\section{I know when it is important to focus and when to relax.}

This question examines whether respondents have skills in the distribution of work and rest. The negative answer indicates unawareness when it is the best time to work or rest. 
The diary disclosed that respondents do not plan or sometimes think they are not able to plan their work and rest time. They state that if it is impossible to change the schedule of certain event, then the process of planning is impossible and meaningless.

\section{Whatever I do, I try to do it perfectly.}

The answer shows how seriously the respondents are determined and strive for excellence. If the answer is no, respondents do not even try to perform work perfectly; it is possible to connect this answer with the answer to question No. 2 - the respondent does not have clear learning objectives.

\section{I have enough free time.}

If the answer is positive, respondents most likely are able to plan their free time more properly and achieve better results in having a balanced working and resting time. Unfortunately, respondents do not have enough time, as time is "eaten" by unwanted timewasters.

The way time is planed shows what kind of person is and who wants to be. Vaitkevičius (2003) states, those who care about their future, worry about time management, i.e. a way to control and plan our time.

\section{Analysis of research data and discussion}

According to the weekly diary of respondents, data on sleep, nutrition, science, personal hygiene, and leisure hours per day were grouped and represent the average distribution of hours per week (168). Five hours per week, respondents devote to eating and personal hygiene. These two activities took the least amount of research time. Given that personal hygiene and nutrition are perhaps the main indicators of well-being, students should pay special attention to this more responsibly.

The studying comprised 34 hours of all-week time. Although this is not a very serious deviation from the recommended 40 hours per week, the remaining 6 hours should still be used for studying. All learning hours are extremely vital, and especially first-year students should spend most of their time reading and researching.

More hours are devoted to sleep. On average, students spend 51 hours a week for sleeping. This is far more hours than for studying, but none of them reached the recommended 56 hours of optimal sleep. In addition, diary analysis revealed complete chaos in students' sleep mode. Students do not follow any sleep patterns, for instance stay up late till 3 am or longer, then sleep when they feel very tired or during a short break after lectures. The first step they should take when planning time is to balance their sleep patterns. Poorly rested students are neither efficient nor psycho-emotionally strong. This naturally leads to a decline in motivation for studies and its further consequences.

Most of the time ( 78 hours) is spent at leisure. This number of hours includes a trip to the lectures and back, a trip home and back to the city of study in Kaunas. 


\section{(7i) IECHNIUM

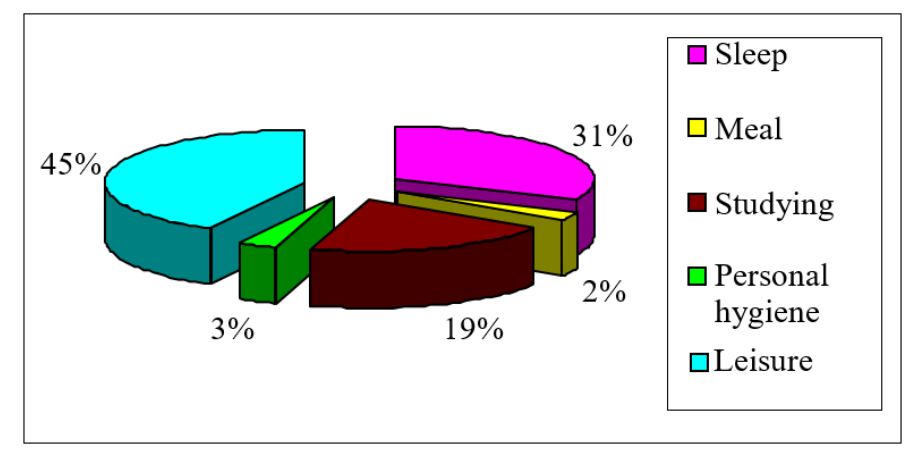

Chart 1. Average weekly work and rest time allocation.

Thus, the statistics for the distribution of time are as follows: the total number of hours per week makes $100 \%$, i.e. $2 \%$ is devoted to meals, $3 \%$ is devoted to personal hygiene, $29 \%$ of the total hours are devoted to studying, sleep occupies $31 \%$ of the time and $45 \%$ is devoted to leisure.

The average work and rest daily hourly balance based on the diary will be discussed below. Here, leisure activities include such activities as personal hygiene, eating and travelling to lectures.

Monday. There is an equal amount of time allocated for studies and sleep, namely, for six hours to each. Thus, free time leads. Even twelve hours were allocated for it.

Tuesday. Time distribution on Tuesday is not even. Students spent too much time studying and sleeping at the expense of leisure hours. Ten hours were allocated for studies and sleep, and only four hours for leisure.

Wednesday. Five hours were devoted to sleep, twelve hours to study, and seven hours to rest. Thus, on Wednesday, students spent too much time studying and exceeded the recommended working time by an average of four hours. This distribution of time leads to fatigue and disability.

Thursday. The balance between studying and sleep time is quite different on Thursdays. It is obvious that this distribution was due to the peculiarities of the lecture schedule. On this weekday, twelve hours were devoted to sleep and four hours to studying. Meanwhile, leisure time comprises eight hours. Since the students slept little on Wednesday and spent a lot of time studying, they report that their fatigue affected study results and the overall day was counterproductive.

Friday. Nine hours for sleep, three hours for studying, twelve hours for rest. It should be noted that there is not enough time to studying the second day in a row. Free time exceeds the recommended number of hours by 4 hours.

Saturday. Saturday is considered a working day in Lithuania and the study time was significantly longer than during the previous two days, i.e. on an average as much as seven hours. Meanwhile, sleep and leisure time are unbalanced. There are five hours allocated for sleeping and twelve hours for leisure. Students had free time at the expense of sleep.

Sunday. Sunday data reflect what was expected; namely, most hours were devoted to sleep - on an average nearly thirteen hours. Free time comprises eleven hours. There was no time to study at all. It can be argued that the data is not critical because Sunday is not a working day.

Having studied and analysed the data and stricken an average, it can be concluded that the time management of the respondents is quite poor. First-year students spend too much time on leisure and too little time on sleep. The total weekly average of sleep, studying, and rest is 
far from the norm and is very irregular and even chaotic when looking at the daily distribution of time.

The analysis of the diary revealed that students rely more on precursors rather than on the guidance of qualified academic staff, which prevents from optimal planning and goal setting. Some indirectly related challenges to time management were revealed, namely, homesickness and lack of feeling being associated with, or being a part of the institution they belong to now. Respondents indicated that twelve years at secondary school made it their home, and it is what they miss at university. This partially explains why students feel homesick, and instead of being at lectures, they prefer staying at home and search for information about academic life and lectures via Facebook distantly. 95\% of those respondents who live in periphery leave campus on Thursday evening despite the fact that they have lectures on Friday. This state of facts determines a high percentage of leisure time in respondents' diaries. Respondents also indicate that after two months of studies, they feel tired and depressed and have to force themselves (sometimes unsuccessfully) to leave home for university.

The lack of sleep is also closely related to the problem of study costs, vitally necessary employment, and mid-semester tests and seminars period. All these problems eventually lead to insufficient rest and dissatisfaction of academic life. All finance students and nearly half of language students started working in the city of university prior studies in summer and continued working when lectures started, regardless of whether they received a state-funded or paid position. Desire to earn and be independent prevents from participation in lectures, and consequently, extra money gives occasion for spending it.

Thus, living by such rhythm, in two months when mid-semester tests session begins, students are tired, sleepless and depressed.

Though first-year students indicated some difficulties adapting to different teaching style, expectations and workloads, in general, they indicated that the infrastructure, such as labs, library, study areas or access to Internet and other facilities provided by universities did not cause time planning problems and were mentioned as very helpful and even excessive comparing to secondary school potential.

Thus, it is not surprising that respondents living in this rhythm for four months feel tired, depressed and often incapacitated. The study clearly showed that not too much workload determines this condition and a lack of basic knowledge on how to manage time.

\section{Conclusions}

The survey established students' work and rest current mode and revealed that the respondents have no time work and rest management skills. Students should pay more attention to planning and setting priorities.

First-year students spend too little time on learning (34 hours) and too much time $(42 \%)$ on leisure activities. Sleep hours are too short - 53 hours comparing to recommended 56 hours. A poor psychological state mentioned in the diary is indicated only when students are not prepared for classes or have not completed assignments, spent little time studying and had not rested. This psychological-emotional state of the respondents is closely related to time management skills. A lot of free time is wasted due to unnecessary time wasters (guests, phones, social media), as respondents are unable to say that they are busy and cannot postpone the communication to a later time. Thus, first-year students must learn or be taught to set goals grouping the day's assignments according to its importance and urgency, i.e. prioritize day activities and assignments. Universities should organise interviews and discussions on time management for first-year students, to expand on the university course of Introduction into Studies on the basis of this research results, to offer additional to existing orientation and first- 
year student support programs that would help to dissociate from secondary school and integrate to university life. This should be done by professional academic staff rather than or along with social networks. To have successful results, students, in turn, must demonstrate a personal interest in time planning, prove their willingness and motivation.

\section{References}

[1] A. PETROVSKIS, N. NEPOMNIAŠ?IAJA, V. MUCHINA, et al.: Amžiaus tarpsni? ir pedagogin? psichologija : mokymo priemon? pedagoginio instituto studentams, 1987.

[2] A. THURBER: Experiences From The Field, Homesickness And Adjustment In University Students. Journal of American College Health, Vol. 60 No.5 (2012), 415-418.

[3] B. RICKINSON, D. RUTHERFORD: Increasing undergraduate student retention rates. British Journal of Guidance and Counseling, 2, 161-172, (1995).

[4] C. McINNIS: Researching the first year experience: Where to from here. Higher Education Research and Development, 20, 2001, 105-114.

[5] C. McINNIS: Signs of disengagement: responding to the changing work patterns of fulltime undergraduates in Australian universities: Higher Education in the 21st Century, London: Elsevier, 2002.

[6] C. SINCLAIR: Understanding University. Maidenhead Open University press, 2006.

[7] C. WILLIAMS: The early experiences of students on Australian campuses. Sydney: University of Sydney, 1982.

[8] G. PURVANECKIEN?: Ly?i? skirtumai švietimo sistemoje. Vilnius, 2000, 92-93.

[9] J. GOLDFINCH, M HUGHES: Skills, Learning Styles and Success of First Year Undergraduates, Active learning in higher education, vol.8 (3) 259-274 DOI: (10.1177/1469787407081881)Moore, (2007).

[10] J. KRALIKAUSKAS: Psichologijos ?vadas, 1998, 296-299.

[11] J.V. VAITKEVI?IUS: Laiko vadyba. Šiaur?s Lietuva, 2003, 6-9.

[12] K. HILLMAN: The first year experience: The transition from secondary school to university and TAFE in Australia. In Longitudinal Studies in Australian Youth, Research Report No 40. Camberwell, Vic: Australian Council for Educational Research, 2005.

[13] L. BROWN: Encounters With Racism and The International Student Experience, Studies in Higher Education, 2013, Vol. 38, No. 7 , $1004-100$

[14] M. WINTRE, M. YAFFE: First-year students' adjustment to university life as a function of relationships with parents. Journal of Adolescent Research, 15(1), 9-37, (2000).

[15] N. TRUSWELL: Student depression on the increase. The Independent, 08 July 2008 Available at:http://www.independent.co.uk/student/news/student-depression-on-theincrease-862336.html, Accessed on 30 July 2019.

[16] P. GREENBANK: From foundation to honours degree: The student experience. Education and Training, 49(2), 91-10, 2007, 2.

[17] Patvirtinti ? valstybines aukšt?sias mokyklas priimam? student? skai?iai. Accessed on 2020 Jaunuary 12]. Accessed at: < https://bakalauras.lamabpo.lt/2019-m-priimtuju-iaukstasias-mokyklas-skaiciai/ $>$.

[18] R. COOKE, M. BARKHAM, K. AUDIN, M. BRADLEY: Student Debt And Its Relation To Student Mental Health. Journal of Further and Higher Education; Vol.28 (2004) 54-66. DOI:(10.1080/0309877032000161814).

[19] R. JAMES, K. KRAUSE, C. JENNINGS: The first year experience in Australian universities: Findings from 1994 to 2009. Centre for the Study of Higher Education, 
University of Melbourne, 2010.

[20] R. ROBERTS, J. GOLDING, T. TOWELL, S. REID, S. WOODFORD: Mental and physical health in students: The role of economic circumstances. British Journal of Health Psychology 2000, 289-297.

[21] S. RAMSAY, L. ELPHINSTONE, K. VIVEKANANDA: Utilising an organisational learning approach to facilitate change in a university and improve the retention of first year students. Proceedings of 11th International Conference on Post-compulsory Education and Training, at Gold Coast, Australia, 2003.

[22] T. KANTANIS: The role of social transition in students' adjustment to the first-year of university. Journal of Institutional Research, 9(1), 100-110, (2000). 